\title{
The Difference of Travel Service Quality Attributes of Travel Service Provider According to Information Search Channel
}

\author{
Changsuk Chun \\ Dept. of Tourism Management Namseoul University \\ 91 Daehak-ro, SeungHwan-eup Seobook-Gu, Cheonan, Korea \\ cschun@nsu.ac.kr
}

\begin{abstract}
The Purpose of this study is to understand the important service quality attributes of travel service providers according to information sources. It is important to understand the differnec of service quality attributes which is important when consumers make a decision to purchase travel service. The three major channels using for information gathering to purchase travel service are known as interpersonal channel, service provider channel, and internet. Six core components of service quality are identified, namely, personal service, convenience system, customer relationship, reputation, responsiveness, and accessibility. We confirm that the important service quality attributes of tourism service providers are significantly different according to the level of information search efforts in every three information search channel.
\end{abstract}

Keywords: Information Channel, Service Quality Attribute, Travel Service Provider

\section{Introduction}

The Internet has emerged as a huge information complexity of travel business, especially in the process of information search of travel service. The Internet makes information search behavior easier than any other information search methods. In case of travel business, the costs of travel products depend heavily on the element suppliers of tourism like hotels, restaurants, attractions, and airlines. This cost condition of tourism products created low-margin model of travel service providers. These low-margin conditions eventually make low promotional and advertising budget allotment in their business. Small and medium-sized travel business also have little budget and experts for market research and communication strategy. But the newly emerged technologies of information and communication such as Internet, mobile communication technology including smartphone had a significant influence on the decision-making process of consumers and those smart gear could be a successful source of communication between small and medium-sized travel business and consumers [1]. The Internet have changed the manner of information search and business advertising and now travelers use search engine on their desktop computer at home or use mobile phone to log in the internet homepage to find useful information. Some consumers prefer to call on the travel agency directly to gather and confirm the relevant information. At last, some of them love to communicate with people who have same interest and expert-level knowledge and information [2]. Customers want to choose any information channel which suitable for his any circumstances or use multi-channel at once for best information. Thus to understand customer's favorite or accustomed information contexts according to various information channels are important for small and medium-sized travel enterprises' success on this fierce competition era. Many of travel related service providers having both website and offline physical office and even they have employees to help customers problems. What

Received (June 19, 2017), Review Result (September 13, 2017), Accepted (September 15, 2017) 
the customers want to have information primarily in a sense of information channels the customers applied to get needed information. In travel service business there is a slim chance to exist as an internet only company because the nature of travel service. Therefore, many travel related service providers have website for transactional means with their valuable and curious customers. This study tries to explore the difference of service quality attribute of tourism service provider when consumers use different information search channels. To understand the differences of service quality attribute (SQA) according to information search channel will improve its service to its customers.

\section{Literature Review}

\subsection{Information Search Behavior and Channel for Travel Related Service}

The purpose of information search behavior is to reduce the risk of purchase and particularly in case of service products; high degree of uncertainty, information search behavior is more sophisticate. Products with strong service attributes make us search information especially through interpersonal information source [3]. Touristic behavior was correlated with high involvement and high involvement situation also required more information regarding service quality attribute [4]. The construct of opinion leadership was adapted to find out the impact of interpersonal communication in the context of small products and fashions [5]. According to studies, the personal influence on the decision making process was much powerful in case of service products like travel service, food, wine, and movies. From a reliability point of view, personal information source was important and have more influence. Word-of-mouth known as one of the interpersonal influence communication methods also has more credibility than advertising messages. Nowadays travelers use the interpersonal information channel through friends, colleagues and family members who had enough experience and knowledge. Travel agency also played important role in the field of information distribution channel for a long times and it was one of the traditional and popular source of tourism information [2]. However, not only the information technology but the professional knowledge and attitude of employees in travel business also have a significant influence on the discussion of customers. In case of complicated routs, multi-destinations, a reputable travel agent can save time, money, and uncertainty. Internet based on-line information search channel is currently the most widely used information channel for tourism products. Internet has changed the whole environment of information search method and made it much easier and faster for customers. The Internet had changed the manner of information search and business advertising. Recently, information is not provided by travel agents exclusively but the traveler himself is often and influential a tourism information provider. Many SNS websites provide travel blogs and social networks for travel service on the Internet [6]. Many studies examined the information search behavior based on the time of trip planning, type of service products, the cost of information search and found that travelers used multiple information sources with different purposes under different reasons [7].

\subsection{Service Quality Attributes in Travel Related Service Provider}

Studies on service quality dimensions on touristic contexts are strongly related with revisitation and satisfaction of consumers and many studies on tourism e-service quality are also associated with customer satisfaction and repurchase [8]. In this study, we tried to explore the difference of service quality dimensions according to multiple information channels which the consumers use. Online SERVQUAL studies found out dominant service quality dimensions including reliability, efficiency, privacy, and customer service [9]. We have previewed several papers not only from e-service quality dimension of tourism contexts but from service quality of e-travel service. Regarding e-travel service quality, many studies tried to construct the measurement scale or develop the reliable 
measurement instrument. One of these studies using the data from online travel service purchasers who was mainly college students reported five factors extracted from initial 44 scale items are information quality, security, website functionality, customer relationships, and responsiveness [10]. A study on the comparison of perception of service quality between internet purchasers and non-internet purchasers, they suggest that the most significant differences between them are security and responsiveness, second. Internet non-purchasers doubt about the use of credit card in website, the risk of sensitive personal information [11]. With another approach, we had also reviewed the tradition studies on service quality attributes of travel related service providers for off-line information channel like visiting the physical offices. The fierce Internet competitions in travel service business, some travel agent in China had focused on the target customers' perception of overall satisfaction and tried to find out service quality dimension for offline travel agent. This research found core five factors from 25 scale items, namely, responsiveness, empathy, corporate image, tangibility, and customer relationships [12]. One of early studies using SERVQUAL model for the evaluation of travel agent service quality produced six factors, namely, corporate image, responsiveness, competitiveness, kind employee, accessibility, and reliability. These six service factors explained 63.5 percent of the total variance [13]. A research tried to develop the measurement instrument for service quality of travel agents in Turkey, this research using 217 questionnaires and found that the core 6 factors, namely, nice employees, prompt service, employee responsiveness, convenience system, image \& reputation, and safe in transaction [14]. Finally, we taking into account the common factors of service quality attributes including many scale items. In this research, we had adopted common factors of service quality attributes from the both offline and online service quality attributes.

Table 1. Previous Research for Service Quality Dimension

\begin{tabular}{|c|c|c|c|c|c|c|c|c|c|}
\hline \multirow{2}{*}{$\begin{array}{c}\text { Dimension of } \\
\text { SQA }\end{array}$} & \multicolumn{4}{|c|}{$\begin{array}{l}\text { Studies on On-line } \\
\text { Service Quality }\end{array}$} & \multirow{2}{*}{$\begin{array}{c}\text { Dimension of } \\
\text { SQA }\end{array}$} & \multicolumn{4}{|c|}{$\begin{array}{l}\text { Studies on Off-line } \\
\text { Service Quality }\end{array}$} \\
\hline & [8] & [9] & {$[10]$} & [11] & & [3] & [12] & [13] & [14] \\
\hline Customer service & $\mathrm{O}$ & & & $\mathrm{O}$ & Personal service & $\mathrm{O}$ & & $\mathrm{O}$ & $\mathrm{O}$ \\
\hline Personalization & & & $\mathrm{O}$ & $\mathrm{O}$ & $\begin{array}{c}\text { Convenience } \\
\text { system }\end{array}$ & & $\mathrm{O}$ & $\mathrm{O}$ & $\mathrm{O}$ \\
\hline Ease of use & & & $\mathrm{O}$ & $\mathrm{O}$ & Empathy & $\mathrm{O}$ & & $\mathrm{O}$ & $\mathrm{O}$ \\
\hline Reliability & $\mathrm{O}$ & $\mathrm{O}$ & $\mathrm{O}$ & & $\begin{array}{c}\text { Customer } \\
\text { relationships }\end{array}$ & & $\mathrm{O}$ & $\mathrm{O}$ & $\mathrm{O}$ \\
\hline Access & $\mathrm{O}$ & $\mathrm{O}$ & & & Accessibility & & $\mathrm{O}$ & $\mathrm{O}$ & \\
\hline Security & & $\mathrm{O}$ & $\mathrm{O}$ & $\mathrm{O}$ & Safety & $\mathrm{O}$ & $\mathrm{O}$ & & \\
\hline Responsiveness & $\mathrm{O}$ & & $\mathrm{O}$ & & Responsiveness & & $\mathrm{O}$ & $\mathrm{O}$ & \\
\hline Information quality & $\mathrm{O}$ & & $\mathrm{O}$ & & $\begin{array}{l}\text { Corporate } \\
\text { Image }\end{array}$ & $\mathrm{O}$ & $\mathrm{O}$ & & \\
\hline $\begin{array}{c}\text { Website } \\
\text { functionality }\end{array}$ & & $\mathrm{O}$ & $\mathrm{O}$ & $\mathrm{O}$ & Reputation & & & $\mathrm{O}$ & $\mathrm{O}$ \\
\hline Efficiency & $\mathrm{O}$ & $\mathrm{O}$ & & $\mathrm{O}$ & Atmosphere & $\mathrm{O}$ & $\mathrm{O}$ & & $\mathrm{O}$ \\
\hline
\end{tabular}

Table 1 presents the previous studies on service quality of on-line and off-line contexts. The selected service quality dimensions for this survey were personal service, convenience system, reputations, customer relationship, accessibility, and responsiveness (refer to Table 2). The questionnaire includes 20 items of on \& off-line service quality attributes (SQA) from the six service quality dimensions. Respondents were asked to 
check the importance of service quality attributes when they are in search of travel-related service through their preferred type of information search channel (refer to Table 3).

Table 2. Selected Dimension for Research

\begin{tabular}{|c|c|c|c|}
\hline & $\begin{array}{c}\text { Online service quality } \\
\text { attribute }\end{array}$ & $\begin{array}{c}\text { Offline service quality } \\
\text { attribute }\end{array}$ & $\begin{array}{l}\text { Dimensions in this } \\
\text { research }\end{array}$ \\
\hline \multirow{9}{*}{$\begin{array}{c}\text { Dimension } \\
\text { of SQA }\end{array}$} & Customer service & Personal service & \multirow{9}{*}{$\begin{array}{c}\text { Personal service } \\
\text { Convenience- } \\
\text { system } \\
\text { Reputation } \\
\text { Customer- } \\
\text { relationship } \\
\text { Accessibility } \\
\text { Responsiveness }\end{array}$} \\
\hline & Information quality & Corporate image & \\
\hline & Ease of use & Convenience system & \\
\hline & Website functionality & Reputation & \\
\hline & Efficiency & Atmosphere & \\
\hline & Reliability & Customer relationships & \\
\hline & Personalization & Empathy & \\
\hline & Access & Accessibility & \\
\hline & Responsiveness & Responsiveness & \\
\hline
\end{tabular}

\section{Research Methods}

\subsection{Collecting and Analyzing the Data}

The survey was conducted in major tour operators and travel-related service providers in Seoul city for two weeks during January of 2017. The sample was made up of 300 respondents. Respondents visited travel agency to consult travel-related service for their vacation. The interviews were administrated by the assistants. They distributed the questionnaires and explained when respondents had questions at on-site. Finally, 288 questionnaires were returned, yielding a response rate of 96 percent. The survey questions to measure the influence of information channels on service quality attribute of travel service provider were based on the previous major studies (refer to the Table 1, Table 2). The collected data was analyzed using 'Statistical Package for Social Science': PASW Statistics 18. And Statistical techniques such as factor analysis and multivariate analysis of variance were used to achieve the objectives of this study.

Table 3. Composition of Questionnaire

\begin{tabular}{|c|c|c|}
\hline Classification & Theoretical Background & $\begin{array}{c}\text { No. of } \\
\text { Question }\end{array}$ \\
\hline $\begin{array}{c}\text { Service quality } \\
\text { attribute (SQA) }\end{array}$ & $\begin{array}{c}\text { Zeynep Filiz(2010), Chaang-Iuan Ho, et el, (2007) } \\
\text { Zeithaml, et el(2002), Fodness, et el(1999) } \\
\text { Carey, et el(1997), LeBlanc(1992) } \\
\text { Parasuraman, et el (1988) }\end{array}$ & 20 \\
\hline $\begin{array}{c}\text { Information } \\
\text { search channel }\end{array}$ & $\begin{array}{c}\text { Angel Diaz-Chao, et el., (2015) } \\
\text { Carmen M. Sabiote-Ortiz, et el.,(2014) } \\
\text { Zheng Xiang et, el., (2014) }\end{array}$ & 6 \\
\hline $\begin{array}{c}\text { Demographic } \\
\text { Characteristics }\end{array}$ & & 4 \\
\hline
\end{tabular}

\subsection{Research Model and Hypotheses}

The purpose of this research was to find the difference of important service quality attributes of travel service provider when consumers approach information search behavior through three different kinds of information channels including interpersonal source, travel service provider, and Internet source. Based on the model (Figure 1) this 
study proposes following hypotheses to explore the difference of service quality attribute of travel service provider according to three different information search channels.

H1: Service quality attribute of travel-related service provider show significant difference according to information search channel.

H-1: Interpersonal information search will show significant difference on service quality attribute.

H-2: On-the office premise information search will show significant difference on service quality attribute.

H-3: Internet information search will show significant difference on service quality attribute.

$\mathrm{H} 2$ : Service quality attribute of travel-related service provider show significant difference between the two groups; high level information search group and low level information search group.

H2a. The level of interpersonal information search efforts will show significant difference on service quality attribute.

$\mathrm{H} 2 \mathrm{~b}$. The level of office information search efforts will show significant difference on service quality attribute.

H2c. The level of Internet information search will show significant difference on service quality attribute.

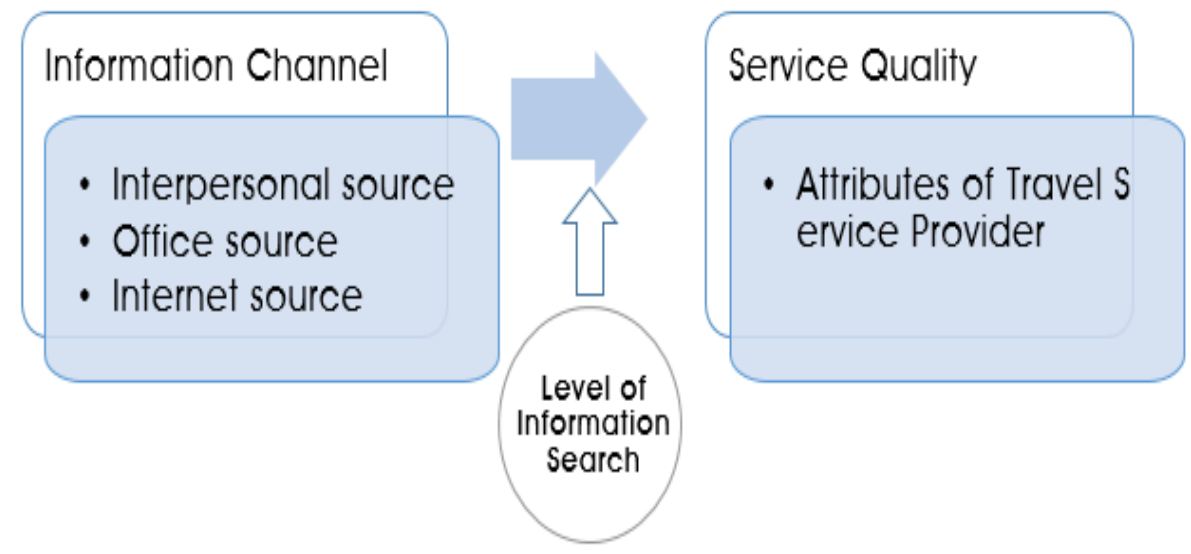

Figure 1. General Framework of Research

\subsection{Participants}

The demographic characteristics of respondents are summarized below in Table 4. The sample was made up of 288 customers who have experienced the overseas travel through travel agents for vacation. Approximately 58 percent (167) were female and remaining 42 percent (121) represented male. As for the age group, 35.4 percent of the respondents were in the range of $40-49 ; 22.5$ percent, 30-39; 20.1 percent, 50-59. In terms of information channel they had used for gathering the information of travel related service providers like travel agent, credit card companies, they had asked to select just one of three information channel. Respondents replied internet; 44.1 percent, travel service provider; 31.6 percent, opinion leader; 24.3 percent. 
Table 4. Demographic Characteristics of the Sample

\begin{tabular}{|c|c|c|c|}
\hline \multicolumn{2}{|c|}{ Classification } & Frequency & Percent (\%) \\
\hline Gender & Male & 121 & 42.0 \\
& Female & 167 & 58.0 \\
\hline \multirow{3}{*}{ Age } & $10-19$ & 20 & 7.0 \\
(n=288) & $20-29$ & 42 & 15.0 \\
& $30-39$ & 65 & 22.5 \\
& $40-49$ & 102 & 35.4 \\
Education & 50-59 & 59 & 20.1 \\
(n=288) & High school or lower & 26 & 9.0 \\
& 2-year College & 88 & 30.5 \\
& University & 125 & 43.4 \\
& Graduate or higher & 49 & 17.1 \\
\hline Occupation & Company employee & 98 & 34.0 \\
(n-288) & Public servant & 47 & 16.3 \\
& Student & 48 & 16.6 \\
& Self-employed & 33 & 11.4 \\
& Professional & 17 & 5.9 \\
& Housewife & 18 & 6.2 \\
Information & Unemployed & 27 & 9.6 \\
Channel & Opinion leader & 70 & 24.3 \\
(n=288) & Travel agent & 91 & 31.6 \\
& Internet & 127 & 44.1 \\
\hline
\end{tabular}

\section{Results}

\subsection{Factor Analysis}

To assess the reliability and unidimensionality of each scale, factor analysis was performed. Table 5 presents the results of factor analysis of independent variables regarding the important service quality attributes. A total of 20 scale items abstracted from the former researches focusing on both on line and off line service quality. The 20 items all have enough loading more than 0.6 and 20 scale items were adopted for final factor analysis.

Table 5. Factor Analysis of Service Quality Attribute (SQA)

\begin{tabular}{|c|c|c|c|c|}
\hline Factor and Items & No. of items & $\begin{array}{c}\text { Eigen } \\
\text { Value }\end{array}$ & Variance & Alpha \\
\hline Personal service & 4 & 6. & 30.4 & 0.842 \\
\hline Convenience system & 4 & 2. & 15.1 & 0.804 \\
\hline Customer relationship & 4 & 2. & 9.0 & 0.762 \\
\hline Reputation & 3 & 1. & 6.3 & 0.724 \\
\hline Responsiveness & 3 & 1. & 5.2 & 0.713 \\
\hline Accessibility & 2 & 1. & 3.2 & 0.652 \\
\hline
\end{tabular}

Kaiser-Meyer-Olkin Measure of Sampling Adequacy $=0.865$, Sig. $=0.000$ $69.2 \%$

Bartlett Test of Sphericity $=3562.537$, Total Percent of Variance Explained $=$

The six factors (personal service, convenience system. customer relationship, reputation, responsiveness, and accessibility) which were rotated by Varimax and extracted by Principal Component Analysis (PCA) had eigenvalues greater than 1 respectively. The six factors explained 69.2 percent of total explained variance. As measured by Cronbach alpha, the results of reliability test for the six extracted factors 
were obtained at $0.842,0.804,0.762,0.724,0.713$, and 0.652 , respectively. The results demonstrated that all the scales had relatively high reliability and suitable for further analysis. The six derived factors were named as personal service, convenience system, customer relationship, reputation, responsiveness and accessibility.

\subsection{Analysis of Variance}

The first hypothesis of the study is to find the significantly different service quality attributes according to the three major information channels. And Hypothesis 2 is to find the significant service quality attribute according to the level of information search efforts. To verify this question ANOVA analysis was adopted. The six factors previously identified through factor analysis and interpersonal information search were entered. The overall model fit for ANOVA analysis was assessed by $F$ statistics and model was statistically significant at $p<0.001$. Table 6 showed the four factors, namely, personal service, convenience system, customer relationship, and responsiveness had significant importance when people searching travel related service quality information through interpersonal source. The implication of this result is customers want to get information mostly about personal service $(F=51.967, p<0.01)$, customer relationship $(F=43.973$, $p<0.01)$ through interpersonal information source. To assess the hypothesis 2 , we had divided the data into two groups with high level of information search group and low level of information search group by the means of respondents' reply on each information channel items. To find the most significant service quality factors for those who have high level of information search efforts, we use multivariate analysis of variance (MANOVA). Table 6 presents the results of MANOVA and we find that four factors of service quality showed significantly more important to the high level of information search group. With high level of information search group put more importance on personal service, customer relationship, and convenience system. But the service quality information for responsiveness showed negative value to interpersonal source. This means that responsiveness is not the important service quality for whom using interpersonal source as an information channel. Finally, we can conclude that the determinant service quality factor to decide the level of information search efforts is personal service.

Table 6. Interpersonal Information Search on SQA

\begin{tabular}{|c|c|c|c|c|}
\hline \multirow{2}{*}{ Factor } & \multicolumn{2}{|c|}{$\begin{array}{c}\text { The level of Information } \\
\text { Search via Interpersonal } \\
\text { Source }\end{array}$} & \multirow{2}{*}{ F } & \multirow{2}{*}{ Sig. } \\
\cline { 2 - 3 } & Low & High & & \\
\hline Personal service & -0.476 & 0.246 & 51.967 & 0.000 \\
\hline Convenience system & -0.234 & 0.210 & 9.723 & 0.003 \\
\hline Customer relationship & -0.431 & 0.223 & 43.973 & 0.002 \\
\hline Responsiveness & 0.201 & -0.102 & 8.325 & 0.004 \\
\hline \multicolumn{7}{l}{ Wilk's Lambda $=0.2153 \quad \mathrm{~F}=23.021$} & \\
\hline
\end{tabular}

The six factors previously identified through factor analysis and travel service provider as an information search channel were performed. The overall model fit for ANOVA analysis was assessed by $\mathrm{F}$ statistics and model was statistically significant at $\mathrm{p}<0.001$. Table 7 showed that the four factors, namely, accessibility, reputation, customer relationship, and convenience system had significant importance when people searching service quality information through travel service providers. The implication of this result is customers want to get information mostly about accessibility $(F=58.638, p<0.01)$, reputation $(F=33.726, p<0.01)$ through travel service providers. To assess the hypothesis 
2, we had followed the first procedures and divided the respondents group with two groups; high level of information search efforts group and low level of information search group. Table 7 presents the results of MANOVA and we can conclude that the determinant service quality factor to decide the level of information search efforts using travel related service provider as an information source is accessibility and convenience system is not the important service quality for whom using travel service provider source as an information channel.

Table 7. Office Visitation Information Search on SQA

\begin{tabular}{|c|c|c|c|c|}
\hline \multirow{2}{*}{ Factor } & \multicolumn{2}{|c|}{$\begin{array}{c}\text { The level of Information } \\
\text { Search via Office Visit }\end{array}$} & \multirow{2}{*}{ F } & \multirow{2}{*}{ Sig. } \\
\cline { 2 - 4 } & Low & High & & \\
\hline Convenience system & 0.108 & -0.153 & 1.877 & 0.003 \\
\hline Customer relationship & -0.232 & 0.262 & 29.481 & 0.001 \\
\hline Reputation & -0.319 & 0.236 & 33.726 & 0.000 \\
\hline Accessibility & -0.397 & 0.322 & 58.638 & 0.000 \\
\hline & Wilk's Lambda = $0.1883 \quad \mathrm{~F}=28.978$ & \\
\hline
\end{tabular}

To find the significantly important service quality attributes when people using internet as an information channel, we adopted ANOVA analysis. Table 8 showed that the four factors, namely, convenience system, customer relationship, personal service, and responsiveness had significant importance when people searching service quality information through internet. To understand the significantly important service quality factor for those who had high level of information search efforts through internet, MANOVA analysis was performed. Table 8 showed that four factors of service quality showed significantly more important to the high level of information search group. With high level of information search efforts group using internet have more importance on convenience system, customer relationship, personal service, and responsiveness. Finally, we can conclude that the determinant service quality factor to decide the level of information search efforts through internet is convenience system.

Table 8. Internet Information Search on SQA

\begin{tabular}{|c|c|c|c|c|}
\hline \multirow{2}{*}{ Factor } & $\begin{array}{c}\text { The level of Information } \\
\text { Search via Internet } \\
\text { Source }\end{array}$ & \multirow{2}{*}{ F } & \multirow{2}{*}{ Sig. } \\
\cline { 2 - 4 } & Low & High & & \\
\hline Personal service & -0.125 & 0.158 & 12.255 & $0.000^{*}$ \\
\hline Convenience system & -0.357 & 0.291 & 47.929 & $0.000^{*}$ \\
\hline Customer relationship & -0.252 & 0.197 & 25.723 & $0.033^{* *}$ \\
\hline Responsiveness & -0.196 & 0.125 & 7.561 & $0.001^{*}$ \\
\hline \multicolumn{7}{|l}{ Wilk's Lambda $=0.6518 \quad \mathrm{~F}=27.408$} \\
\hline
\end{tabular}

\section{Conclusion}

The research revealed that there are significant differences on service quality attributes of travel related service providers according to information search channels and also confirmed that the level of information search efforts had significant influence on service quality attributes. Analysis of variance was adopted to find the significantly important 
service quality factors according to the three major information search channels. We find that there are significantly different service quality factors according to information channel. According to the findings consumers talk with people like friends, relatives, acquaintances to gain the travel-related service quality information particularly about personal service. The other three service quality dimensions including customer relationship, convenience, and responsiveness were also important factors for those who were engaged in interpersonal information search. People visited travel service providers like travel agents to gain the information regarding accessibility, reputation, customer relationship and convenience. The most important service quality attribute for those who with high level efforts on visiting office was accessibility dimension. With regards to Internet information search, the factors of convenience, customer relationship, personal service, and responsiveness were important service quality factors. The most important information of service quality factors for high level internet users was convenience factor including payment method, detailed products information, safe \& easy reservation system, and concierge service for related service. A multivariate analysis of variance was also conducted to find the most significantly important service quality factor for those who have high level of information search efforts. The results showed that the most important service quality factor for those who have high level of information search efforts through interpersonal source is personal service. People using interpersonal source trying to find out the various personal services attributes including professional \& kind employees, fast responses, and plenty time for discuss the itinerary. We have also find high level of information search group through travel-related service provider showed that accessibility is the most significant and important factor. People visiting travel agent want to know the information regarding extra working time and convenience of location. Lastly, the high level of information search group through internet showed that convenient system is the most significant and important service quality factor. People access to internet try to find the ease of cancellation and changes of reservation and new and up-dated information of travel service. Understanding the differences of service quality attributes according to various information search channels will be useful and helpful to establish on \& off-line communication strategies for travel related service providers.

\section{Acknowledgments}

"Funding for this paper was provided by Namseoul University".

"This paper is a revised and expanded version of a paper entitled [The Influence of Information Search Channel on Service Quality Attributes of Tourism Service Provider] presented at [NGCIT 2017, Ho chi Min Vietnam, August 16-18, 2017.

\section{References}

[1] D.-C. Angel, M.-I. Oriol and T.-S. Joan, "Information and Communication Technologies, Innovation and Firm Productivity in Small and Medium-Sized Travel Agencies: New Evidence from Spain", Journal of Travel Research, vol. 55, no. 7, (2015), pp. 862-873.

[2] M. Sabiote-Ortiz Carmen, F.-J. Dolores and C.-G. Alberto, "Overall Perceived Value of a Tourism Service Delivered via Different Media: A Cross-Cultural Perspective", Journal of Travel Research, vol. 55, no. 1, (2014), pp. 34-51.

[3] D. Fodness and B. Murray, "A Model of Tourist Information Search Behavior", Journal of Travel Research, vol. 37, no.3, (1999), pp. 220-230.

[4] Ute Jamrozy, S. Backman and K. Backman, "Involvement and Opinion Leadership in Tourism", Annals of Tourism Research, vol. 24, no. 4, (1996), pp. 908-924.

[5] T. L. Childers, "Assessment of the Psychometric Properties of an Opinion Leadership Scale", Journal of Marketing Research, vol. 23, (1986), pp. 184-187.

[6] Z. Xiang, D. Wang, J.T. O'Leary and D. R. Fesenmaier, “Adapting to the Internet: Trends in Travelers' Use of the Web for Trip Planning", Journal of Travel Research, vol. 54, no. 4, (2014), pp. 511-527.

[7] S. H. Jun, C. A. Vogt and K. J. MacKay, "Relationship between information search and travel product purchase in pretrip contexts", Journal of Travel Research, vol. 45 no. 3, (2007), pp. 266-277. 
[8] M. E. Mohammed, G. M. Wafik, S. G. Abdel-jalil and Y. A. Hassan, "The Effects of E-Service Quality Dimensions on Tourisy's e-Satisfaction”, Int'1 Journal of Hospitality \& Tourism Systems, vol. 9, Issue 1, (2016), pp. 250-267.

[9] A. Zeithaml, A. Parasuraman and A. Malhotra, "Service Quality Delivery through Web Sites: A Critical Review of Extant Knowledge", Journal of Academy Marketing Science, vol. 30, no. 2, (2002), pp. 362376.

[10] C.-I. Ho and Y.-L. Lee, "The Development of an e-Travel Service Quality Scale”, Tourism Management, vol. 28, (2007), pp. 1434-1449.

[11] Z. Yang and M. Jun, "Consumer perception of e-Service Quality: from Internet Purchaser and NonPurchaser Perspectives", Journal of Business Strategies, vol. 19, no. 1, (2002), pp. 19-41.

[12] H. Zhun, "Service Quality of Travel Agents: The Case of Travel Agents in China", Proceedings of International Conference on Service System \& Service Management, vol. 05, (2005), pp. 533-537.

[13] G. LeBlanc, "Factors Affecting Consumer Evaluation of Service Quality in Travel Agencies: An Investigation of Customer Perceptions", Journal of Travel Research, Spring, (1992), pp. 10-16.

[14] Z. Filiz, "Service Quality of Travel Agents in Turkey", Qual Quant, no. 44, (2010), pp. 793-805.

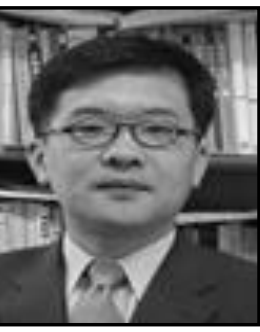

\section{Author}

Changsuk Chun, he received his Ph. D. degree in tourism from Sejong University, Korea, in 2001. He had joined the department of tourism management of Namseoul University in 2001. Currently, he, as a professor, is teaching and studying tourism marketing. 